\title{
REGISTRO DE MÁSCARAS EN SIERRA DE LA VENTANA DE LA REGIÓN PAMPEANA ARGENTINA. PRESENTACIÓN DE EXPLICACIONES ALTERNATIVAS
}

\section{RECORDS OF MASKS IN SIERRA DE LA VENTANA, PAMPEAN REGION OF ARGENTINA: ALTERNATIVE EXPLANATIONS}

\author{
FERNANDO OLINA*
}

\begin{abstract}
El conjunto rupestre de la región pampeana sudamericana está constituido fundamentalmente por motivos abstractos y rectilíneos, y en bajo porcentaje se reconocen motivos "figurativos". Entre este tipo de "diseños" se encuentran representaciones escasas y puntualmente distribuidas de "máscaras" registradas en solo dos sitios de los treinta y cuatro con pinturas rupestres del sistema de Ventania de la provincia de Buenos Aires, República Argentina. La vinculación con otros motivos de máscaras semejantes, en áreas lindantes, indicaría la expresión, en un contexto acotado de la transición patagónica pampeana, de una particularidad de códigos comunes compartidos al menos por una parte de la población que ocupó este territorio. Sobre la Gruta de los Espíritus, uno de los sitios estudiados aquí con presencia de "máscaras", existen relatos etnohistóricos, así como de tiempos contemporáneos, que informan sobre la reutilización de este sitio por parte de comunidades indígenas trasandinas para la realización de rogativas, revalorizando este espacio como lugar de resignificación simbólica.
\end{abstract}

Palabras clave: máscaras, región pampeana, simbolismo

The rock art repertoire of the Pampean region consists primarily of abstract and rectilinear motifs and a low percentage of "figurative" motifs. Among these designs are a few "mask" representations found in just two of the thirty-four parietal art sites in the Ventania Range of Buenos Aires Province, Argentina. The association of these with similar mask motifs found in bordering areas points to the representation of similar expressions in a limited context within the Patagonian-Pampean transition. Regarding Gruta de los Espiritus, the investigation of one site with masks yielded ethno-bistoric and contemporary accounts reporting the reuse of this site by trans-Andean indigenous communities for the purpose of prayer, revaluing this space as a place of symbolic resignification.

Key words: masks, Pampean region, symbolism

\section{INTRODUCCIÓN}

En la región pampeana sudamericana, localizada en los países de Argentina y Uruguay, una de las connotaciones más fuertes del registro arqueológico simbólico son las pinturas rupestres, mayoritariamente abstractas, reconocidas en sus diferentes ambientes serranos (Gradin 1975, 1977; Consens 1995, Consens \& Oliva 1999; Mazzanti \& Valverde 2003; Podestá et al. 2011). En este contexto, temas como movilidad, estrategias de subsistencia, circulación de información, simbolismo y ritualidad resultaron sustanciales en las investigaciones arqueológicas del sistema de Ventania (Oliva 2000, 2006; Oliva et al. 2010). Específicamente, en estas serranías se registraron treinta y cuatro sitios con arte rupestre, los cuales presentan características similares a otros de la región pampeana. Este conjunto rupestre presenta un repertorio de motivos abstractos geométricos pintados en color rojo, que incluyen, entre otros, líneas paralelas, zigzags, triángulos opuestos por el vértice y un porcentaje muy bajo de motivos "figurativos" manos, antropomorfos- (Oliva 2000; Oliva \& Algrain 2004, 2005; Oliva et al. 2010). Estas representaciones han sido asignadas a la tendencia abstracta geométrica compleja, en adelante TAGC, siguiendo criterios propuestos por Podestá, Bellelli y colaboradores (Bellelli et al. 2008; Podestá et al. 2008), estableciéndose de esta manera la vinculación de este conjunto rupestre con

* Fernando Oliva, CEAR Centro de Estudios Arqueológicos Regionales de la Facultad de Humanidades y Artes de la Universidad Nacional de Rosario, Argentina, email: fwoliva@unr.edu.ar 
representaciones semejantes no solo de otros sectores de la región pampeana, sino con sitios del norte de la Patagonia y del sector central de la República Oriental del Uruguay (Podestá et al. 2011). Dentro de este conjunto se reconoció un tipo muy particular de motivos para la región pampeana: las representaciones de "caras", "rostros antropomorfos", "mascariformes" o "máscaras", términos que se han usado indistintamente por diversos autores (González 1989; Shobinger 2002; Mazzanti \& Valverde 2003; Troncoso et al. 2008) y que en este trabajo se asume que las mismas pueden ser asignadas como "máscaras", dadas sus características formales de representación. Estos motivos se encuentran solamente en tres sitios de la región pampeana: Haras Los Robles, -sistema de Tandilia- (Mazzanti \& Valverde 2003), sitio 1 Alero Corta Pies y Gruta de los Espíritus -sistema de Ventania-, conformando un evento estético muy particular, ya que constituyen "marcas" muy específicas de los sitios donde se encuentran. Asimismo, evidencian una relación formal y estructural con motivos similares representados en otro sector de latitudes medias de la República Argentina, en el sur de Mendoza (fig. 1) (Schobinger 1978, 2002). Por otra parte, la escasa representación de estos tipos de motivos en el sector norte de la región patagónica y la ausencia de su registro en gran parte del territorio patagónico constituyen, sin dudas, elementos significativos no menores en la consideración del estudio de las máscaras (Menghin 1957; Casamiquela 1981; Boschin 2009).

Con relación a la Gruta de los Espíritus existen relatos etnohistóricos (Bengoa 1987; Mora Penroz 1998; Bechis 1999) y de tiempos contemporáneos que informan sobre la reutilización de este sitio por parte de comunidades indígenas trasandinas para la realización de rogativas.

Las diferentes evidencias arqueológicas o etnográficas aquí enunciadas ofrecen un marco interpretativo que se considera válido para el estudio de las representaciones en estudio. De esta manera, el arte rupestre de Ventania se transforma en una vía de abordaje central para la comprensión de los parámetros estéticos de las sociedades originarias y su visión sobre "el todo" que los rodea, que incluye diferentes formas de relacionarse con el universo y la comunidad. En este sentido, se asume que la perspectiva estética puede contribuir a la búsqueda de interpretaciones que se vinculan con la apropiación de determinados motivos y de los sitios donde estos se encuentran representados. Para tal fin, se exponen evidencias arqueológicas y etnográficas que aportan a la comprensión de las estructuras sociales e ideológicas de los grupos originarios que habitaron la región pampeana.

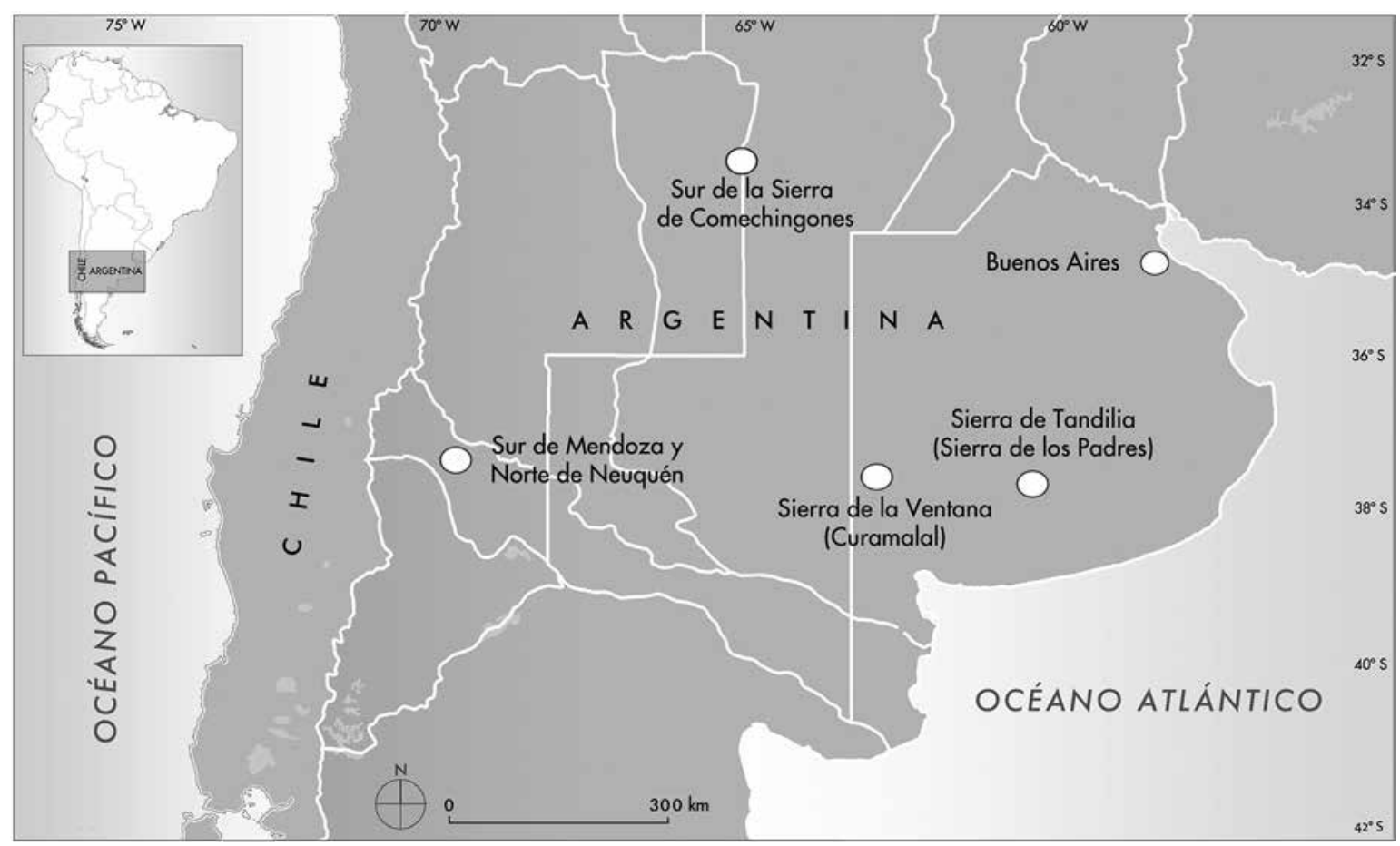

Figura 1. Mapa de ubicación de las áreas donde se localizan motivos de "rostros antropomorfos", "caras", "mascariformes" o "máscaras" en distintas regiones del centro de la República Argentina.

Figure 1. Map showing location of motifs with "anthropomorphic faces," "faces," "mask-shapes" or "masks" in different regions of central Argentina. 
Uno de los objetivos de este trabajo es proponer explicaciones vinculadas con la ejecución de motivos de máscaras en sitios localizados en la Sierra de la Ventana por los grupos humanos que en diferentes momentos ocuparon este sector de la región pampeana.

\section{ALGUNAS CONSIDERACIONES TEÓRICAS PARA EL ANÁLISIS}

La determinación de "territorios" específicos por los grupos sociales implica la ocupación y por lo tanto la apropiación de determinados espacios en donde se lleva a cabo su subsistencia (Jochim 1981; Giménez \& Héau Lambert 2007), así como los vínculos establecidos y la constitución de las respectivas identidades (Mantha 2009). En este sentido, es necesario considerar la movilidad como un mecanismo continuo adaptativo y sustancial mediante el cual se permite explotar el territorio y sus recursos, minimizar el riesgo y, fundamentalmente, aumentar el grado de información (Gamble 1990). Las vinculaciones entre los grupos cazadores recolectores y determinados espacios geográficos se encuadran en situaciones de apropiaciones territoriales funcionales y simbólicas, las cuales se establecen como construcciones de pertenencia a específicos territorios por los diferentes grupos a lo largo de la historia de su ocupación. Se estima que la comprensión de los aspectos iconográficos y de su entorno en sociedades de economías primitivas, así como de las vinculaciones que se establecen con otros grupos sociales, en escala macro regional, son claves para la interpretación de la constitución de estas sociedades.

El estudio de las sociedades cazadoras recolectoras comprende universos diversos, como, por ejemplo, la vinculación de estos grupos humanos con el empleo de los recursos ambientales de manera generalizada o compleja (Hayden 1981), o bien clasificaciones que establecen dentro de una lógica dicotómica la subdivisión en grupos simples o complejos (Keeley 1988). Dada esta amplia gama de posibilidades, se cree que en el estudio del registro rupestre realizado por las sociedades que habitaron en el sistema de Ventania resulta operativo, y por lo tanto oportuno, considerar el abordaje estético como una herramienta de análisis válida, tal como lo propone Thomas Heyd en varios de sus trabajos (Heyd 2003). En esta dirección, se estima que la estética en el arte rupestre abarca el estudio de las marcas grabadas o pintadas hechas por el hombre -como objetos de percepción- sobre una superficie rocosa. Es en esta relación donde se busca establecer una mejor comprensión del arte rupestre y de la manera en que este puede servir al reconocimiento de las cualidades perceptibles de determinados tipos de motivos. Al mismo tiempo, se busca establecer la comprensión de los mecanismos de vinculación entre las diferentes apropiaciones de las imágenes y de las características de los sitios de arte rupestre, así como el uso al que fueron sometidos por generaciones anteriores en los sitios en que están emplazados. De esta manera se incluyen los diversos aspectos relevantes para la apreciación de una imagen de arte rupestre, de un panel o de un conjunto de sitios, en determinados contextos culturales y localizaciones geográficas, cuando son la base para experiencias perceptuales particulares.

Leroi-Gourhan (1971) considera que la naturaleza de la estética funcional responde más claramente a un verdadero determinismo mecánico, articulando más con leyes de la materia que de lo viviente, lo cual explica que su naturaleza sea idéntica en el mundo vegetal animal o humano. En este último sentido, el valor estético global reside en la medida en que las fórmulas mecánicas conservan su valor a través del velo de las superestructuras figurativas. Lévi-Strauss (1981), por su parte, postula que cada grupo étnico posee una necesidad universal de elaborar un orden, una interpretación simbólica del mundo, es decir, la identidad del hombre y la diversidad de sus actos evidenciados en obras. A partir de las mismas operaciones formales se genera una multiplicidad de organizaciones en la vida social ante los nuevos y cambiantes objetos y la existencia de una convergencia entre lo universal y lo particular; de esta manera, entre naturaleza y cultura existiría un intercambio recíproco.

Morphy (1994), a su vez, conceptualiza la estética como la capacidad humana y su tendencia de adjudicar propiedades cualitativas a un estímulo. Su estudio es importante para entender fenómenos como la percepción, apreciación y comprensión. Heyd (2003-2004) propone que la apreciación estética implica la valoración de algo, ya que cuando algo es apreciado se le atribuye un cierto valor; el enfoque está orientado a las cualidades formales de ese objeto, su composición y la manera en que se relacionan su forma y su contenido, además de los efectos que busca crear sobre el observador. Las cualidades estéticas están vinculadas con la capacidad de ciertos objetos de atraer la atención e impactar sensorialmente más que otros; el valor que se les asigna a estos objetos deriva en parte del impacto que provocan. En este contexto se asume que determinados sectores del paisaje o 'lugares' han ejercido una atracción diferencial sobre las poblaciones humanas (Ingold 1986; Wandsnider 1992), influyendo de este modo activamente en la toma de decisiones respecto del uso de un lugar específico para la realización de 
determinadas actividades. Casimir (1992) propone que en áreas con mayor densidad poblacional o de ecología especialmente variada, las comunidades allí residentes muestran una mayor preocupación por definir sus derechos de una forma explícita. De acuerdo con lo anterior, se estima apropiado poder recurrir a diversos medios, como es la utilización de un lenguaje de signos, mediante el cual se dejan mensajes en puntos específicos del paisaje, los cuales pueden contener una mezcla de información sagrada y profana. El rasgo esencial de todo ello es que los sujetos pueden comunicarse en forma indirecta al estar presentes en el mismo lugar de forma simultánea (Ingold 1986). Por lo cual se considera que la representación de iconos gráficos es una de las vías más directas para este tipo de comunicación.

\section{EL REGISTRO ARQUEOLÓGICO DE "MÁSCARAS" EN AREAS PRÓXIMAS A SIERRA DE LA VENTANA}

\section{El registro arqueológico rupestre del norte de la Patagonia}

En el sector norte de la región patagónica, donde fluyen los ríos Negro y Colorado, se registra un número importante de sitios con arte rupestre pertenecientes a diferentes contextos temporales. Albornoz (2003) informa sobre las investigaciones rupestres realizadas en diferentes áreas norpatagónicas de la provincia de Río Negro en los últimos treinta años. Para tal efecto, subdivide el norte patagónico en tres sectores: oeste, área de osque y sudeste de Río Negro. En el oeste se reconoce parte del estilo de miniaturas propuesto por Menghin (1957) y los trabajos del equipo Boschin (1986, 2009). En el área boscosa lacustre cordillerana, en la zona de los lagos Nahuel Huapi, Gutiérrez, Mascardi y de los ríos Manso y Villegas, se reconoce la labor de Hajduk \& Albornoz (1999), quienes han aportado importantes elementos para la comprensión del arte rupestre presente en esta área. Finalmente, el último sector investigado es el sudeste rionegrino en la meseta de Somuncura (Albornoz $\&$ Pereda 2010). Por lo expresado, se puede sintetizar, en primer lugar, que en las investigaciones del norte de la Patagonia hay un predominio de motivos grabados y pintados pertenecientes a representaciones de motivos abstractos, como grescas, algunos motivos figurativos, como pisadas de félidos o camélidos y otros que evidencian el contacto hispano-indígena (caballo); es decir, un conjunto que muchos autores han incorporado a la TAGC (Podestá et al. 2008). Resulta significativa la poca presencia de motivos de "máscaras" (Boschin 2009), registro que se encuentra escasamente representado dentro del amplio repertorio de motivos presentes en el territorio patagónico (Menghin 1952, 1957). Del análisis de las publicaciones editadas, las citas bibliográficas referidas a la representación de máscaras para estas latitudes son llamativamente escasas. Del conjunto de información publicada es importante considerar la referida al sitio Sarita 1 (Pilcaniyeu), provincia de Río Negro, en cuyo sector V, Boschin (2009: 153) informa:

en la porción abajo-centro del soporte, en la que se ubicaron los grabados más tempranos, se discriminaron 6 motivos $(1,17 \%)$ de la clase geométricos, grupo figuras, subgrupo círculos, tipo tres alineados, cuya morfología coincide con uno de los diseños que Carmen Nahueltripay (cfr. Casamiquela 1960ª) identificó con la denominación, en mapudungun, "kollón nëpën" cuya traducción literal es dibujo de la máscara.

Otro aporte interesante, también brindado por esta investigadora se refiere a la idea de una "boca del kollon" (máscara), la cual considera que presentaría una amplia dispersión geográfica, expresando: "El registro de los dientes de la máscara kollón, en Piedra Bonita de Beroiz, que tiene la frecuencia más alta de motivos funerarios, sugiere que Elumgássüm pudo ser parte de las ceremonias especializadas de la muerte" (Boschin 2009: 330).

\section{El registro arqueológico rupestre de otras áreas vecinas}

Con el fin de contextualizar las investigaciones, en el acápite siguiente se informa sobre los estudios vinculados con el registro de máscaras en algunos sectores relevantes de áreas vecinas a Sierra de la Ventana. En primer lugar, en Río Cuarto (Córdoba) en las sierras de los Comechingones, específicamente en el cerro Intihuasi, se informa sobre cinco aleros con representaciones poligonales abiertas y cerradas pintadas en colores rojo, blanco, ocre, y abundantes superposiciones (Rocchietti 1990; Gili 2000). Un relevamiento especial es la representación de una "máscara", en el Alero de la Máscara, en un panel con mayor grado de caos y con una disposición imbricada de poligonales que dificultan la percepción y discriminación de las mismas" (Gili 2000: 133). Por otra parte, en la provincia de San Luis, Consens (1986) realizó una síntesis con una base de 111 sitios -64\% pinturas, 46\% grabados-, relevando 2100 motivos mayormente abstractos rectilíneos, combinaciones poligonales diversas, pocos motivos figurativos (zoomorfos y antropomorfos) con solo $0,14 \%$ de representaciones correspondientes a "mascariformes" (íd. 1986 1: 209). En el Norte Chico de Chile, en la cuenca hidrográfica del Limarí y en los valles de Choapa y Elqui, Grete Mostny \& Hans Niemeyer (1983), considerando investigaciones 
previas de fines de la década del cuarenta, establecieron una importante clasificación de los diferentes tipos de máscaras y definieron el Estilo Limarí, el cual presenta un tema, que caracterizan como el "más popular", constituido por la representación de "grandes cabezas humanas de corte cuadrangular, enmascaradas y premunidas de tiaras o atavíos cefálicos muy complejos" (Mostny \& Niemeyer 1983: 54-58). Troncoso y colaboradores, a partir de sus estudios en el valle del Choapa, efectuaron una revisión crítica del Estilo Limarí y las relaciones existentes entre valle El Encanto, Estilo Limarí y complejo cultural El Molle, criticando el reduccionismo de su definición dada la amplia variedad de diseños y técnicas de producción (Troncoso et al. 2008). Estos autores consideran necesaria la segregación en conjuntos diferenciales, a partir de la versatilidad técnica, iconográfica y espacial, para poder determinar variabilidades internas en los conjuntos, definidos básicamente por sus diseños, relaciones espaciales al interior del sitio y de los bloques, así como por sus características técnicas. Las diferencias registradas conllevan a considerarlos como producciones culturales de distintos momentos y que descansan sobre lógicas de producción divergentes. Así, un grupo correspondería a las pinturas, un segundo a grupos de cabezas tiara surco profundo y un tercer grupo integrado por motivos vinculados con la elaboración de surco superficial. Esta situación expresaría construcciones visuales diferentes y, por lo tanto, responden a lógicas y períodos históricos y culturales distintos: Arcaico Temprano, Alfarero Temprano, e Intermedio Temprano y Tardío (íd. 2008: 23-25). Finalmente, Cabello (2011) redefine estos rostros antropomorfos para el "valle de Chalinga" (Chile) como "representaciones a partir de un marco", en lugar del empleo del término máscara. Otros estudios vinculados con el registro de máscaras se ha aplicado al oriente de la cordillera de los Andes, en el sur de Mendoza y norte de Neuquén. Shobinger (1978, 2002) da cuenta, además, de una serie de sitios con grabados y pinturas, en las inmediaciones de la cordillera del Viento, lugar en donde se fijaría el límite del "Estilo de Paralelas". En dirección al este y en territorio mendocino, informa sobre las investigaciones en el departamento de Malargüe (Mendoza), destacando los estudios en los sitios Arroyo del Chancay, Arroyo del Moro, Arroyo Chenqueco, Ranquil del Este o del Payen y Puesto de Totoras, donde se han localizado grabados de "cabezas mascariformes" con un repertorio de "cabezas simples", es decir, formadas por un trazo subcircular o subrectangular con tres puntos u hoyuelos indicando ojos y boca. Basándose en estas representaciones propone para Malargüe dos grandes grupos técnico-estilísticos: el primero representado por las pinturas y el segundo por los grabados. En relación con las pinturas propone que las mismas corresponden a una penetración del arte norpatagónico ("Estilo de Grecas" y "Variantes"). Respecto de los grabados, Shobinger sugiere tres modalidades o influencias básicas. La primera vinculada a una tendencia curvilínea típica del área cuyana; la segunda relacionada con el tridígito como elemento del Estilo de Pisada norpatagónico y, por último, la representación de las "cabezas y figuras antropomorfas mascariformes, que serían motivos de raíz andina cuya aparición hasta en la solitaria Payenia meridional constituye toda una sorpresa" (Shobinger 2002: 193).

Finalmente, en el extremo oriental de la región pampeana se localiza el sistema de Tandilia, donde los sitios con arte rupestre rondan en un número aproximado no superior a la docena (Tapia 1937; Ceresole \& Slavsky 1985; Mazzanti 1991). Las representaciones de los mismos están constituidas por reticulados, lineales reticulados con escasos motivos figurativos incluyendo alineamiento de tridígitos y de bidígitos, los cuales en principio son asignados a la TAGC propuesta recientemente en un trabajo para la región (Podestá et al. 2011). Sin embargo, dentro del repertorio presentado, resulta muy significativo el informe de Mazzanti y Valverde sobre un tipo particular de representación registrada en el sitio Haras Los Robles, en el cual establece vinculaciones formales con el registro de máscaras de Sierra de la Ventana, según se informa en el acápite siguiente:

fue registrado un nuevo motivo sobre el borde exterior del techo de un reparo bajo, este es del tipo simple de color rojo que corresponde a una representación figurativa muy obliterada. Es un óvalo $(23 \times 15 \mathrm{~cm})$ con tres trazos cortos en su interior que forman una cara (Mazzanti \& Valverde 2003: 313).

\section{EL REGISTRO ARQUEOLÓGICO DEL SISTEMA DE VENTANIA}

El poblamiento pampeano se ubica en el Pleistoceno Final e inicios del Holoceno Temprano ( $c a .11000$ a 9500 años AP). En este momento la información arqueológica muestra la ocupación del ambiente serrano de Tandilia y de la llanura interserrana, desconociéndose el uso de otros ambientes, como las llanuras al sur de Ventania. Las tareas de investigación de campo realizadas por más de dos décadas en el sistema serrano de Ventania (Oliva 1991, 2000; Oliva et al. 2010) han posibilitado obtener un importante cúmulo de información sobre el paisaje de este sistema serrano, emplazado en el sector sur del Área Ecotonal Húmedo-Seca Pampeana. La Sierra de la Ventana presenta serranías con rumbo norte-sureste $180 \mathrm{~km}$ máxima y $130 \mathrm{~km}$ este-oeste (Schiller 1930). Sus mayores plegamientos se registran en el sector 
occidental, en los cordones de Puan, Curamalal, Bravard y Ventana, cuyas altitudes oscilan entre los 900 y 1248 msnm. Las sierras presentan mayormente un aspecto escarpado, su altitud promedio es de 400-450 m sobre la llanura adyacente y en ella se localizan numerosas cuevas y aleros de profundidades variadas (Schiller 1930; Harrington 1947). En el sector oriental del sistema serrano, constituido por las sierras de Las Tunas y de Pillahuincó, el paisaje presenta laderas más suaves y el número de cuevas y aleros está limitado a algunos pocos casos (Suero 1972). La evidencia arqueológica para los primeros momentos de ocupación del territorio es escasa en el serrano de Ventania (Castro 1983; Oliva 2000). A fines del Holoceno Medio y el Holoceno Tardío ( $c a$. 4500 a 400 años), con la instauración de condiciones áridas-semiáridas en la región pampeana se incrementa la evidencia de ocupaciones en el sistema serrano de Ventania y su llanura adyacente (Austral 1994; Oliva 1991; Oliva et al. 1991a y 1991b). A partir del 1000, las áreas de la región pampeana que concentrarían la mayor densidad poblacional habrían sido Ventania y su llanura adyacente, debido a una probable redistribución de la población existente y a la expansión de otra población procedente del NE de la Patagonia. En efecto, hacia fines del Holoceno Tardío (ca. 1000 a 400 años), hay creciente evidencias arqueológica y bioarqueológica acerca de la expansión de una población humana desde el sector inferior de las cuencas de los ríos Colorado y Negro y del litoral sur bonaerense hacia las llanuras situadas a ambos lados del sistema serrano de Ventania (Barrientos et al. 1999; Oliva 2000). Para momentos del contacto hispánico es relevante la información procedente del sitio Gascón 1, el cual presenta entierros humanos asociados a fauna exótica, cuentas de collar de origen europeo y otros elementos metálicos (Oliva \& Sánchez 2001). En síntesis, las condiciones del paisaje permitieron contar con espacios de habitabilidad garantizada durante el Holoceno -como fueron ocupaciones de sitios en cuevas desde hace aproximadamente 6000 años (Castro 1983; Oliva 2000; Oliva et al. 2010)-; con lugares de aprovisionamiento de materiales líticos (Oliva \& Moirano 1999; Catella et al. 2010); sitios dedicados a diferentes prácticas mortuorias (Barrientos et al. 1999), así como otras estructuras de piedras (Oliva \& Panizza 2012). El paisaje serrano, por lo tanto, es previsible y se transforma en un recurso significativo para el establecimiento de estrategias de vinculación con el medio. Las cuevas y aleros son elementos estables y ubicables, por lo tanto, su localización así como sus características son transmisibles por sucesivas generaciones. En este contexto, algunos sitios presentan características particulares y han estado seguramente provistos de simbolismo en diferentes momentos del Holoceno por las poblaciones que ocuparon el territorio. En tal sentido, resulta atractiva la propuesta de Whitley (1998) para el occidente de Norteamérica, mediante la cual pretende, a partir de aportes procedentes de fuentes etnohistóricas y desde una perspectiva de género, dilucidar las características simbólicas del arte rupestre, planteando que constituirían lugares rituales $\mathrm{y}$, por consiguiente, portales al terreno de lo sagrado.

Particularmente, el sistema de Ventania presenta cientos de aleros y cuevas, de los cuales al presente se han identificado treinta y cuatro sitios con pinturas rupestres. Eduardo Holmberg (1884) elaboró un primer informe a fines del siglo xIx sobre el arte rupestre de la Gruta de los Espíritus (Sierra de la Ventana). A partir de la década del ochenta se lleva a cabo un plan de prospección y relevamiento sistemático de sitios con arte rupestre a través de los estudios coordinados por el autor de este trabajo y colaboradores (Oliva 2000; Oliva \& Algrain 2004, 2005; Oliva \& Panizza 2007; Oliva et al. 2010), quienes han abordado el estudio rupestre mediante diferentes metodologías de análisis. De los treinta y cuatro sitios con pinturas rupestres estudiados se concluye que predomina una tendencia hacia la representación de tipo abstracto-geométrico asignada a la TAGC (Podestá et al. 2011) y conformada por motivos de líneas paralelas, líneas en "v" paralelas, trazos y líneas en zigzag paralelas y líneas en zigzag con recorrido no rectilíneo; tridígitos, peiniformes, figuras poligonales irregulares, rombos, triángulos simples y unidos por el vértice, entre otros. También, aunque en menor número, se registran motivos figurativos diversos - positivo de manos, zoomorfos, antropomorfos- (Oliva 2000; Oliva et al. 2010), y solo dos sitios presentan motivos de tipo "mascariformes" o "máscaras".

En este trabajo se abordan los sitios 1 Alero Corta Pies y Gruta de los Espíritus. Una primera consideración acerca de estos dos sitios es su ubicación estratégica, dado que cada uno de ellos se ubica en entradas al sistema serrano, ambos son fácilmente detectables y con una amplia visibilidad de la llanura adyacente (fig. 2). Desde el sitio 1 del cerro Corta Pies, localizado en una serranía menor alejada del cordón principal del sistema de Ventania, se pueden observar varios kilómetros de la llanura en direcciones sur y noreste; a su vez, desde la Gruta de los Espíritus localizada en el cordón de Curamalal, en el sistema de Ventania, es posible tener un campo visual de varios kilómetros en dirección norte del valle intraserrano próximo y en dirección noresteeste del valle del arroyo Curamalal Grande.

El sitio 1 del cerro Corta Pies es un pequeño alero de unos $3 \mathrm{~m}$ de abertura orientado en dirección suroeste a $233^{\circ}$ y $1,5 \mathrm{~m}$ de profundidad. Se localiza en una estribación de la serranía de Curamalal alejada unos 50 km en 


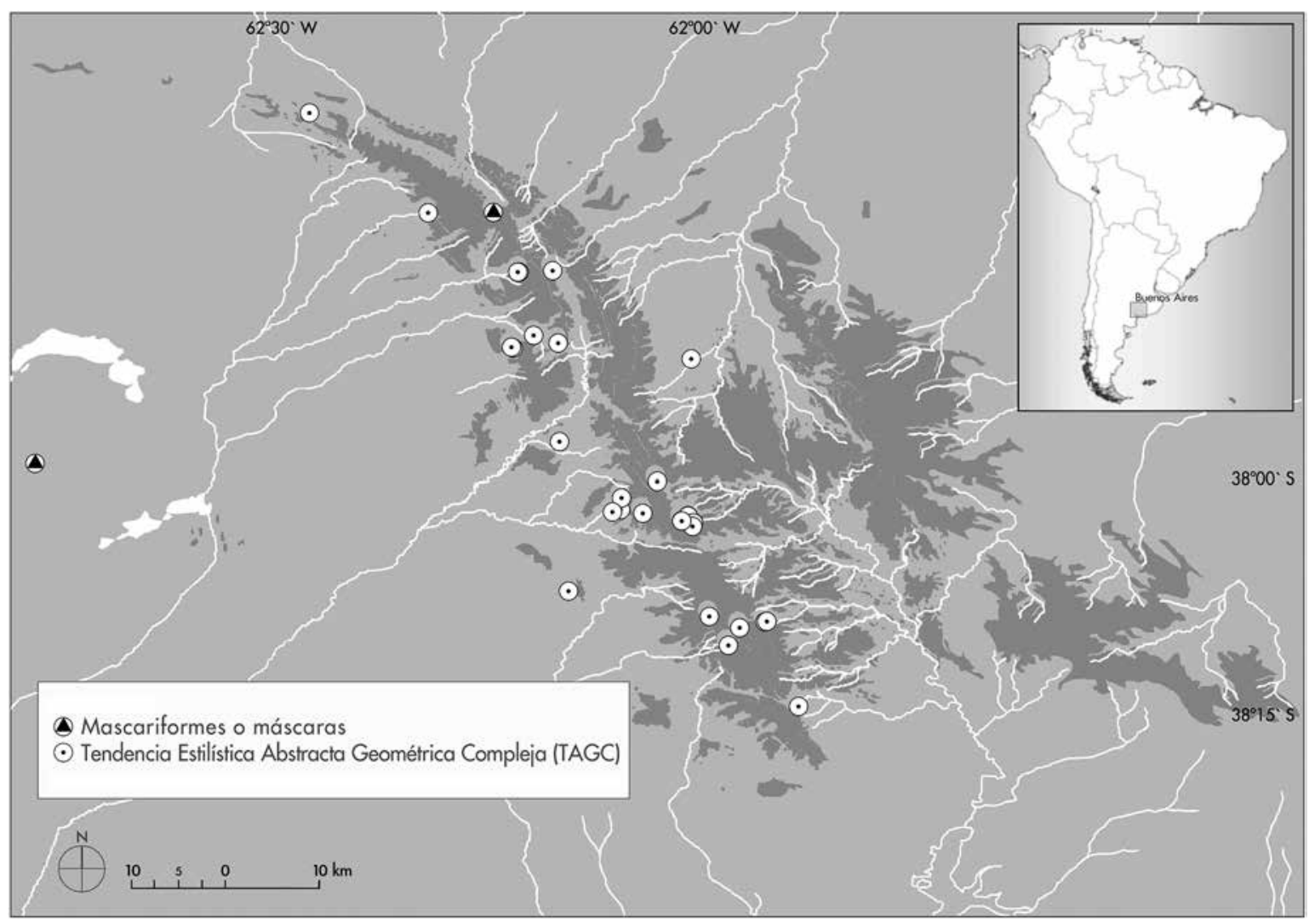

Figura 2. Ubicación de los Sitios 1 Alero Corta Pies y Gruta de los Espíritus y otros sitios con pinturas rupestres del Sistema de Ventania. Figure 2. Location of Site 1, Alero Corta Pies 1 and Gruta de los Espiritus, as well as other rock painting sites of the Ventania System.

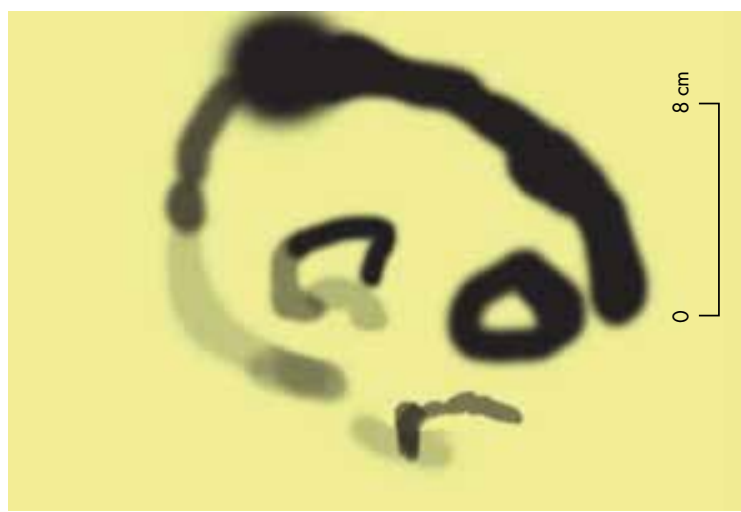

Figura 3. Representación de máscara del Sitio 1, Alero Corta Pies. Figure 3. Representation of a mask from Site 1, Alero Corta Pies.

dirección al este del cordón principal de las sierras y a 296 msnm. En este cerro se ha registrado la representación de un "rostro antropomorfo", mascariforme o máscara subcircular simple (fig. 3) (ver Tabla 1), asociado a un solo motivo de líneas paralelas. El motivo se encuentra en un estado muy desvaído y se ubica sobre la pared oeste del sitio en el sector 1 .
La Gruta de los Espíritus se localiza en el valle intraserrano sobre el cordón de Curamalal, a unos $650 \mathrm{msnm}$ y a una distancia aproximada de 100 y $150 \mathrm{~m}$ de la naciente del arroyo Curamalal Grande. Su abertura es de unos $12 \mathrm{~m}$ de ancho por otros tantos de altura. Esta "boca" se halla orientada a unos $330^{\circ}$, debido al desprendimiento de un sinclinal que se profundiza de manera irregular hasta unos $54 \mathrm{~m}$. Esta característica particular de la cueva es de suma importancia, ya que las investigaciones realizadas en la región y por la información édita arqueológica o geológica no se describe en la sierra de Curamalal otra cueva con las características de la Gruta de los Espíritus (Harrington 1947; Oliva 2000). A fines del siglo xIX, Holmberg (1884) realizó un primer relevamiento de esta cueva e informó sobre doce figuras, aclarando que reproducen una parcialidad, por repetirse en su mayor parte, y que eligió las representaciones que según su criterio se diferenciaban más acentuadamente, describiendo "la gran cantidad de figuras de color rojo, que adornan sus paredes, figuras con las cuales, aparte de toda intención simbólica, se ha querido representar caras humanas, aunque privadas del importantísimo órgano llamado 
Tabla 1. 1: Sitio 1 Cerro Corta Pies; 2: Gruta de los Espíritus; Con: Concentración; S1CCP- MA1: Sitio 1 Cerro Corta Pies, Motivo aislado número ordinal correspondiente; GE-MA1: Gruta de los Espíritus, Motivo aislado número ordinal correspondiente; GE- CO1-1: Gruta de los Espíritus, Concentración correspondiente, número motivo ordinal correspondiente.

Table 1. 1: Site 1, Cerro Corta Pies; 2: Gruta de los Espiritus; Con: Concentration; S1CCP-MA1: Site 1, Cerro Corta Pies, isolated motif of corresponding number; GE-MA1: Gruta de los Espiritus, isolated motif of corresponding number; GE-CO1-1: Gruta de los Espiritus, corresponding concentration, motif of corresponding number.

\begin{tabular}{|c|c|c|c|c|c|}
\hline Sitio & Sector & Con & Motivo & Tipo de Motivo & Publicación \\
\hline 1 & S1 & & S1CCP- MA1 & $\begin{array}{l}\text { MAS 1: Máscara con contorno subcircular con } \\
\text { representación de ojos y boca de cuerpo vacío }\end{array}$ & Este trabajo \\
\hline 2 & S1 & & GE-MA1 & $\begin{array}{l}\text { MAS 2: Máscara sin contorno con representación } \\
\text { de ojos y boca subrectangulares de cuerpo lleno }\end{array}$ & Este trabajo \\
\hline 2 & S3 & 1 & GE- CO1-1 & $\begin{array}{c}\text { MAS 3: Máscara con contorno doble con } \\
\text { representación de ojos y boca subrectangular } \\
\text { de cuerpo lleno }\end{array}$ & Este trabajo \\
\hline 2 & $\mathrm{~S} 3$ & 1 & GE- CO1-2 & $\begin{array}{l}\text { MAS 4: Máscara con contorno subcircular con } \\
\text { representación de ojo derecho y boca de cuerpo lleno }\end{array}$ & Este trabajo \\
\hline 2 & S3 & 1 & GE- CO1-3 & $\begin{array}{l}\text { MAS 5: Máscara con contorno subcircular } \\
\text { con representación de ojos de cuerpo lleno }\end{array}$ & Este trabajo \\
\hline 2 & S1 & & GE-MA2 & $\begin{array}{l}\text { MAS 6: Máscara con contorno subrectangular } \\
\text { con representación de ojos de cuerpos vacíos }\end{array}$ & Este trabajo \\
\hline 2 & S1 & 2 & GE-CO2-1 & $\begin{array}{l}\text { MAS 7: Máscara con contorno subcircular con } \\
\text { representación de ojos y boca de cuerpo lleno }\end{array}$ & Este trabajo \\
\hline 2 & S1 & 2 & GE-CO2-2 & MAS 99: Esbozo de formatización de máscara & Este trabajo \\
\hline 2 & S1 & 2 & GE-CO2-3 & MAS 99 & Este trabajo \\
\hline 2 & S1 & 2 & GE-CO2-4 & MAS 7 & Este trabajo \\
\hline 2 & S3 & & GE-MA-3 & $\begin{array}{l}\text { MAS 8: Máscara con contorno subrectangular triple } \\
\text { con representación de ojos y boca de cuerpo lleno }\end{array}$ & Este trabajo \\
\hline 2 & S2 & 3 & GE-CO3-1 & MAS 7 & Este trabajo \\
\hline 2 & S2 & 3 & GE-CO3-2 & MAS 7 & Este trabajo \\
\hline 2 & S2 & 3 & GE-CO3-3 & $\begin{array}{l}\text { MAS 9: Máscara con contorno subcircular con } \\
\text { representación de ojos y boca de cuerpo vacío }\end{array}$ & Este trabajo \\
\hline 2 & S2 & & GE-MA-4 & MAS 5 & Este trabajo \\
\hline 2 & S3 & 4 & GE-CO4-1 & MAS 7 & Este trabajo \\
\hline 2 & S3 & 4 & GE-CO4-2 & MAS 99 & Este trabajo \\
\hline 2 & $\mathrm{~S} 3$ & 4 & GE-CO4-3 & MAS 7 & Este trabajo \\
\hline 2 & S4 & 5 & GE-CO5-1 & $\begin{array}{l}\text { MAS 10: Máscara con contorno subcircular con } \\
\text { representación de ojos y boca de cuerpo lleno. } \\
\text { Presencia de adorno cefálico interno. }\end{array}$ & $\begin{array}{l}\text { Holmberg } 1884 \\
\text { (L 6-F 4), Oliva } \\
\text { Sánchez } 2001 . \\
\text { Este trabajo. }\end{array}$ \\
\hline 2 & $\mathrm{~S} 4$ & 5 & GE-CO5-2 & $\begin{array}{l}\text { MAS 11: Máscara con contorno subcircular } \\
\text { con representación de ojos y boca de cuerpo vacío. } \\
\text { Presencia de adorno cefálico externo. } \\
\text { Presenta cuerpo con diseño geométrico interno. }\end{array}$ & $\begin{array}{l}\text { Holmberg 1884, } \\
\text { (L 7-F 1), Oliva \& } \\
\text { Sánchez } 2001 . \\
\text { Este trabajo. }\end{array}$ \\
\hline 2 & $\mathrm{~S} 4$ & 5 & GE-CO5-3 & MAS 11 & $\begin{array}{l}\text { Holmberg 1884, } \\
\text { (L 7-F 2), Oliva \& } \\
\text { Sánchez } 2001 . \\
\text { Este trabajo. }\end{array}$ \\
\hline 2 & S4 & 5 & GE-CO5-4 & $\begin{array}{l}\text { MAS 12: Máscara con contorno subcircular con } \\
\text { representación de ojos y boca de cuerpo vacío. } \\
\text { Presenta cuerpo con diseño geométrico interno. }\end{array}$ & $\begin{array}{l}\text { Holmberg } 1884, \\
\text { (L 7-F 3), Oliva \& } \\
\text { Sánchez } 2001 . \\
\text { Este trabajo. }\end{array}$ \\
\hline
\end{tabular}




\begin{tabular}{|c|c|c|c|c|c|}
\hline Sitio & Sector & Con & Motivo & Tipo de Motivo & Publicación \\
\hline 2 & S1 & 6 & GE-CO6-1 & $\begin{array}{l}\text { MAS 13: Máscara con contorno subcircular } \\
\text { con representación de ojos y boca de cuerpo vacío. } \\
\text { Presencia de adorno cefálico externo asociado } \\
\text { a motivo en forma de media luna }\end{array}$ & $\begin{array}{l}\text { Holmberg } 1884 \\
\text { (L6-F } 6 \text { Y 8) } \\
\text { Este trabajo. }\end{array}$ \\
\hline 2 & S1 & 6 & GE-CO6-2 & $\begin{array}{l}\text { MAS 14: Máscara con contorno subrectangular con } \\
\text { representación de ojos y boca de cuerpo vacío. } \\
\text { Presencia de adorno cefálico externo asociado. }\end{array}$ & $\begin{array}{l}\text { Holmberg } 1884 \\
\quad \text { (L6- F 7) }\end{array}$ \\
\hline 2 & S1 & 6 & GE-CO6-3 & $\begin{array}{l}\text { MAS 15: Máscara con contorno subcircular con } \\
\text { representación de un ojo cuerpo vacío y otro ojo y boca } \\
\text { de cuerpo lleno. Presencia de adorno cefálico externo. }\end{array}$ & $\begin{array}{l}\text { Holmberg } 1884 \\
\quad \text { (L6- F 5) }\end{array}$ \\
\hline 2 & & & MA-5 & MAS 7 & $\begin{array}{l}\text { Holmberg } 1884 \\
\quad \text { (L6- F 1) }\end{array}$ \\
\hline 2 & & & MA-6 & MAS 6 & $\begin{array}{l}\text { Holmberg } 1884 \\
\quad \text { (L6- F 3) }\end{array}$ \\
\hline 2 & & & MA-7 & $\begin{array}{l}\text { MAS 16: Máscara con contorno subrectangular con } \\
\text { representación de ojos y boca de cuerpo vacío. } \\
\text { Presencia de adorno cefálico externo asociado. Presenta } \\
\text { cuerpo con diseño rectilíneo interno. }\end{array}$ & $\begin{array}{l}\text { Holmberg } 1884 \\
\quad(\text { L7- F 4) }\end{array}$ \\
\hline
\end{tabular}

nariz" (Holmberg 1884: 36). De las doce representaciones publicadas por Holmberg, en sus figuras $6 \mathrm{y}$ 7 , en la actualidad solo se encontraron evidencias de cinco de ellas, de la figura 6 las ilustraciones 2, 4 y 8 y de la figura 7 las ilustraciones 2 y 3, en estado muy desvaído y algunas casi totalmente destruidas por la acción de grafitis. Las investigaciones en esta cueva se han retomado a principios de este siglo (Oliva 2000) y, debido a que la mayor parte de las representaciones están destruidas por grafitis contemporáneos, fue necesario aplicar tecnología informática para su reubicación (Oliva \& Sánchez 2001). En este trabajo se comunican los motivos registrados parcialmente por Holmberg y por relevamientos que se han realizado en las últimas décadas. Los motivos están representados en dos tonalidades de color rojo y se pueden observar en las figuras 4-6, y su descripción en la Tabla 1.

Entre el conjunto de motivos presentes en esta cueva sobresale la concentración $\mathrm{N}^{\mathrm{0}} 5$, dada la vinculación espacial interna de los motivos que genera un espacio visual de unos $4 \mathrm{~m}^{2}$. Esta concentración está integrada por una máscara circular con adornos cefálicos y por motivos que presentan adosado un cuerpo con diseño geométrico interno, los cuales, por sus características morfológicas y de localización en el sitio, se asume que representan máscaras con atuendos adosados (fig. 6). En síntesis, en el sector de Sierra de la Ventana se registró un total
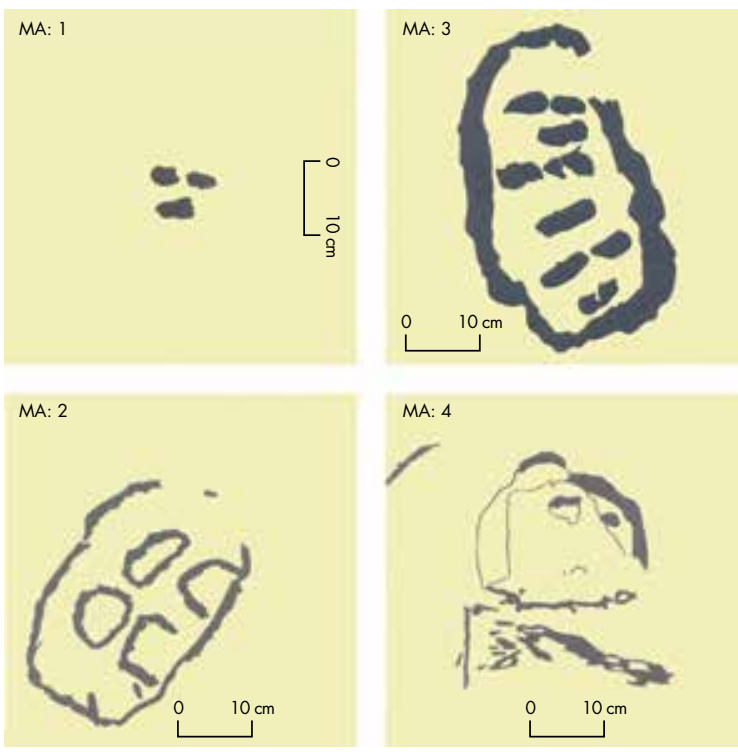

Figura 4. Motivos aislados de máscaras del Sitio Gruta de los Espíritus. Número ascendente de izquierda a derecha y de arriba abajo. Figure 4. Isolated mask motifs at Gruta de los Espiritus site. In ascending order from left to right and top to bottom.

de 28 representaciones de máscaras que comprenden 17 tipos, los cuales se han agrupado en 7 conjuntos de acuerdo con sus características predominantes que se agrupan en la Tabla 2. 
Tabla 2. Variabilidad de conjuntos de máscaras del Sistema de Ventania Table 2. Variability of sets of masks Ventania System.

\begin{tabular}{|c|c|c|c|}
\hline Conjunto & Descripción & Porcentaje & Icono \\
\hline 1 & Máscara de contorno subcircular & $42,85 \%$ & \\
\hline 2 & Máscaras con adornos cefálicos & $14,28 \%$ & \\
\hline 3 & $\begin{array}{c}\text { Máscaras con representación de cuerpo } \\
\text { con motivos geométricos }\end{array}$ & $14,28 \%$ & \\
\hline 4 & Máscara de contorno subrectangular & $10,71 \%$ & \\
\hline 5 & Máscara de contorno subcircular doble & $3,57 \%$ & \\
\hline 6 & Máscara sin contorno & $3,57 \%$ & \\
\hline 7 & Esbozo de "máscara" & $10,71 \%$ & \\
\hline
\end{tabular}



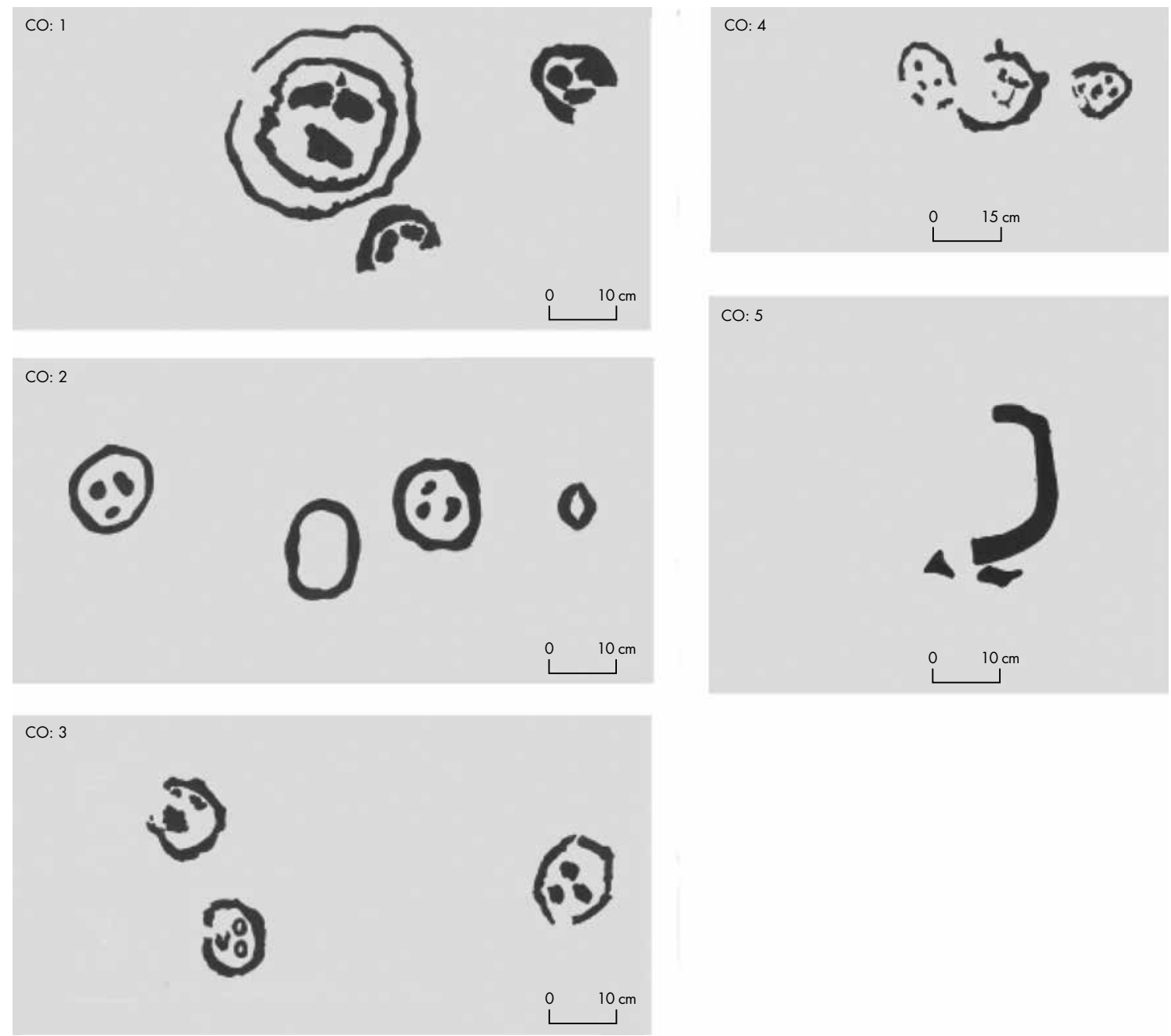

Figura 5. Concentraciones de motivos de máscaras del Sitio Gruta de los Espíritus. Número ascendente de izquierda a derecha y de arriba abajo. Figure 5. Concentrations of mask motifs at Gruta de los Espiritus site. In ascending order from left to right and top to bottom.

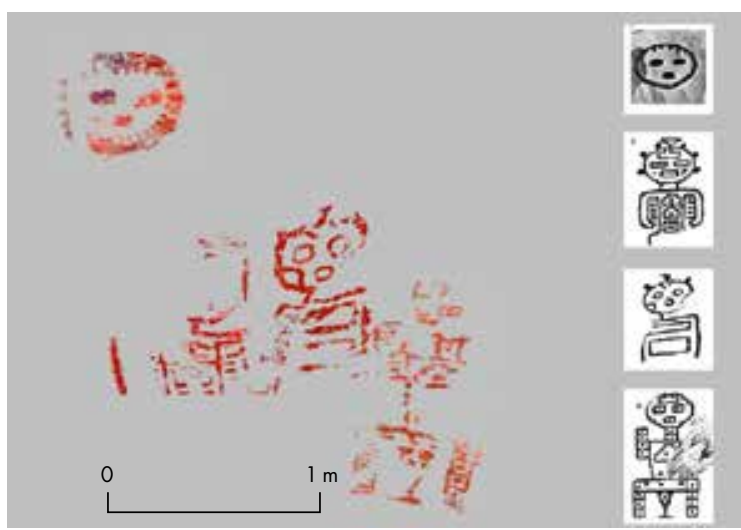

Figura 6. Concentración de motivos número 5 del Sitio Gruta de los Espíritus localizado en el sector noroeste de la cueva.

Figure 6. Concentration of motif 5 at Gruta de los Espiritus site, located in the northwest sector of the cave.

\section{APORTES DE RELATOS RECIENTES}

Los relatos contemporáneos sobre las actividades rituales de las sociedades indígenas abren otra línea interpretativa del arte rupestre pampeano. En tal sentido es oportuno considerar el trabajo de Ouzman (1998: 33), quien reflexiona acerca de "la creencia en que el arte rupestre, o bien las cuevas donde este se emplaza, son entradas a otra realidad". Esta situación puede en principio ser pensada en relación con el repertorio de la TAGC y con el valor simbólico de las representaciones de "manos", tal como ha sido relevado etnográficamente entre los tehuelches o en los relatos mitológicos mapuches relacionados con la estampa de mano (Casamiquela 1981; Priegue 1997).

Específicamente, en vinculación con Sierra de la Ventana existen diversas referencias sobre el conocimiento 
de estas sierras por parte de las sociedades originarias, en tal sentido se puede mencionar el trabajo de Bechis (1999), quien toma la referencia de Bengoa (1987: 102) en donde expone sobre los viajes de las comunidades del lado chileno a fines del siglo xviII y principios del XIX a las sierras de Curamalal, con el fin de realizar ritos de iniciación en estas serranías:

Por otro lado, en las pampas, más específicamente, en las sierras de Curamalal -según le contaban a Lenz a fines de siglo- había una cueva donde se hacía cierto rito de iniciación por el cual los jóvenes araucanos se arreglaban para ser puros guerreros y así volverse invulnerables a las armas. Las pampas atraían y fascinaban a las agrupaciones del lado chileno... se podría sostener que durante el siglo XVIII y XIX el viaje a la pampa se transformó en una especie de ritual de iniciación de los jóvenes guerreros.

Mora Penroz (1998) informa que alcanzar el estado de guerrero entre los mapuches significaba el dominio del cuerpo, de las mentes y de las almas, y conducía al ejercicio de alerta bélica expresada en conceptos como trepeleai tami duam, trepeluwtunge, que significan "mente despierta”. Según Mora Penroz (1998), el guerrero vigilaba frente al enemigo y este nivel de conciencia ofrecía un poder de la visión profunda de las causas ocultas que tejen lo real, es decir, se convertían en videntes. La tradición indígena de Chile explica el fenómeno de hombres que descuellan del común con una especial conexión con fuerzas secretas de la naturaleza, algunos de los cuales se vincularon con grutas mágicas, tal es el caso de Nawelcheu.

Como se desprende de lo citado, se hace referencia a la utilización por parte de sociedades recientes de una cueva en las sierras de Curamalal que por sus características se atribuye a la Gruta de los Espíritus. Mora Penroz (1998: 104) expresa que Nawelcheu fue uno de los múltiples casos que se iniciaron en Kuramalal. Este sitio cercano a Bahía Blanca y al sur de Buenos Aires fue para los mapuches del lado occidental de la cordillera una gruta mágica donde bajo la protección de seres sobrenaturales y la asistencia de los espíritus ancestrales se podía alcanzar el don de ser invulnerable, expresa también que se trataría de una gruta de iniciación guerrera que coronaba el largo "viaje de la madurez", pleno de peligros y pruebas que los varones audaces iniciaban desde la Araucanía chilena como garantía de valor, coraje y mérito de mando. De esta manera, el rito del pasaje central constituía la incorporación en la piel de polvo de la piedra raspado de esas mágicas paredes plenas de signos laberínticos, como una forma de introducir una segunda naturaleza sobrenatural en el cuerpo mortal del guerrero, tal sería el $\ddot{u} k u$ : piedra misteriosa pulverizada inoculada bajo la piel o disuelta en un brebaje místico. Considera que el puelmapu (oriente), horizonte aureolado con signo de grandes proezas, al volver de las pampas y de esa gruta se convertía en kona (guerrero), kalku (brujo) o langemchefe (dominador de poderes felinos).

Agrega Mora Peronz (1998: 104, extraído de Lenz 1895-1897):
Peñi kanai, peñi chu kanai, Amuyu Kuramalal mapu:

Nentumeyayu üku puerta:

Veimeu, veimeu ñuwangeweayu

Peñitu kanai,

Nentumeliyu üku chipuertameu, Veimeu ñuangeayu,

Peñitu kanai...
Hermano, mi querido hermano, vamos a Kuramalal,

vamos a sacar remedio de la puerta

entonces, entonces valientes seremos.

Hermano mío querido,

si sacamos el remedio de la puerta, entonces seremos valientes hermano mío querido.
Tales expresiones que aluden en forma directa a la Gruta de los Espíritus han sido consideradas por diversos autores del campo etnográfico. Al respecto, continúa Mora Penroz (1998: 105):

Kuramalal representa el renü (gruta misteriosa) o bien sitios de reunión (koyactun) de "brujos". Según datos de R. Casmiquela (3) el sitio se transformó tardíamente (degenera) en Salamanca (antro de brujería), no obstante conserva siempre su carácter trascendental y superior de su origen: ser sede del dios de Laberinto (Walichu), cuyas guardas que circunvolucionan sobre la roca pasan a significar "el paso difícil del alma hacia el más allá”. Tales pinturas perfectamente asimilables al trempilcahue ("Balsero de los muertos que circunvolucionan"), y aquí aparecen indisolublemente ligadas a los poderes del Mundo superior de los espíritus que solo se manifestarían a aquellos caciques hechos dignos a la manifestación de ese conocimiento superior de la Naturaleza. Pareciera ser que el sitio no fuera mágico en sí mismo, sino que se tornaría mágico para aquel que pudo adquirir el poder interno de la magia a través del camino, a través de la audacia, los atrevimientos y la constante cercanía de la muerte, esa eficaz consejera de la sabiduría. Por eso se pudo decir de Nangil, a su vuelta de aquella lejana Bahía Blanca, que el sitio debió ser un lugar de poder impregnado y poblado de fuerzas y energías sutiles puestas allí a disposición de los ülmes (hombres notables).

Otro dato interesante respecto de la utilización de la Gruta de los Espíritus y que aporta a la visualización simbólica de este sitio arqueológico está vinculado con un episodio ocurrido en tiempos muy recientes. En la primavera del año 2007, mapuches procedentes de la localidad de Temuco (Chile) realizaron en esta cueva rituales siguiendo la "tradición". Esta información ha sido brindada por el exdirector de Cultura del Municipio de Saavedra, Jorge Capotosti, y por los dueños del establecimiento donde se ubica este sitio. 


\section{DISCUSIÓN FINAL}

Los procesos de expansión y restricción de las poblaciones norpatagónicas en la región pampeana han sido temas ampliamente discutidos en las últimas décadas. En este sentido, se ha propuesto que determinados estilos del arte rupestre y de arte mueble reflejarían la dispersión de poblaciones patagónicas en el sureste pampeano incluyendo la serranía de Ventana. Belardi (2004) formula vinculaciones entre la región pampeana y sur de Cuyo con el centro-norte de la Patagonia, respecto del aumento demográfico y a la fisión de las poblaciones en momentos tardíos. En otras presentaciones se ha tenido en cuenta la vinculación del arte rupestre pampeano con expresiones simbólicas de otras áreas vecinas particularmente del norte de la Patagonia y Cuyo (Consens \& Oliva 1999; Oliva 2000, Oliva \& Algrain 2004; Oliva 2006).

Dos enfoques que vinculan el arte rupestre con información procedente de la etnografía están presentes para las regiones de la Pampa y la Patagonia. En tal sentido, Curtoni (2006), considerando la microrregión pampeana y de norpatagonia, explica las variantes locales de las expresiones artísticas como particularidades de diferentes clanes o linajes. Nacuzzi (1998), a su vez, observa identificaciones étnicas en el norte de la Patagonia y la Pampa, en momentos del contacto hispano-indígena, ligadas a la figura de los caciques, los cuales poseían territorios en los que explotaban determinados recursos.

Particularmente de las 34 cuevas o aleros del sistema de Ventania (Oliva 2000; Oliva et al. 2010; Podestá et al. 2011), el 94\% corresponde a representaciones rupestres adjudicadas a la TAGC, con una cronología que atañe desde el 1500 AP hasta momentos del contacto hispanoindígena. Esta información cronológica es asumida a partir de dataciones radiocarbónicas efectuadas en los sitios La Sofía 2 y La Montaña 1 (Oliva 2000), y considerando algunos motivos que por su morfología son asignados a momentos posteriores a la conquista hispánica, por ejemplo la representación de una embarcación en la cueva Florencio (Oliva et al. 2010). En términos generales, cabe aclarar que el repertorio está constituido por representaciones abstractas rectilíneas, motivos que también se encuentran presentes en otros tipos de soportes en diferentes sitios del Área Ecotonal Húmedo-Seca Pampeana, como placas grabadas y huevos de Rhea (Oliva 2000; Oliva et al. 2010). A su vez, el conjunto rupestre tiene semejanzas formales con otras áreas vecinas de la región pampeana, como los sitios localizados en Lihue Calel en la provincia de La Pampa (Gradin 1975) con aquellos ubicados en el sistema de Tandilia (Mazzanti \& Valverde
2003), y las representaciones de Chamangá en Uruguay (Podestá et al. 2011). También se observan amplias similitudes con motivos representados en el sector norte de la región patagónica, vinculados en todos los casos a la TAGC (Podestá et al. 2008).

A partir de este contexto de investigación pampeano y en especial atención al registro del sistema de Ventania, se centró el estudio en los motivos de "caras", "mascariformes" o "máscaras". La representación de este tipo de motivos es una de las expresiones estéticas más antiguas de la creación humana, ya que por su intermedio se sugiere la doble existencia del hombre: su aspecto esencialmente inmutable y su íntimo contacto con la muerte (Lévi-Strauss 1981). Su culto se remontaría a la necesidad de los hombres de formar parte de las fuerzas que rigen el universo y poder interactuar simbólicamente con ellas; en tal sentido, el "cubrir" el rostro con vestimenta de otros. Por otra parte, se coincide con Heyd (2003) en que el arte rupestre proporciona una novedosa perspectiva sobre la continuidad de la producción de arte entre los seres humanos, con relación a los pueblos que nos precedieron y crearon el arte rupestre, y sobre las tierras en que están ubicadas estas manifestaciones de arte que abarcan tan largos períodos de la existencia humana.

En diferentes latitudes del continente americano las máscaras representan uno de los elementos característicos de manifestaciones asociadas con el culto y el ritual. En vinculación con las representaciones rupestres de "caras", "mascariformes" o "máscaras" presentes en la Gruta de los Espíritus, se plantean tres propuestas alternativas. Un primer razonamiento considera que los ejecutantes de las representaciones rupestres de la Gruta de los Espíritus fueron aquellos que realizaron las representaciones de la TAGC en los otros sitios de la Sierra de la Ventana. Una segunda alternativa propone que los ejecutantes de los motivos en la Gruta de los Espíritus fueron grupos que ocuparon este sitio con posterioridad a aquellas sociedades que realizaron las representaciones de la TAGC en el área de Ventania. Por último, un tercer razonamiento alternativo considera que los autores de los motivos en la Gruta de los Espíritus podrían ser anteriores o contemporáneos de aquellos que realizaron las representaciones de la TAGC, pero la representación de los motivos de máscaras representó una marca territorial sustantiva que se proyectó en el tiempo a través de sucesivas significaciones.

A favor del primer razonamiento propuesto se considera que los ejecutantes de la TAGC representaron solamente las máscaras en la Gruta de los Espíritus y en el Alero 1 sitio Corta Pies, por "específicas decisiones tomadas por los grupos ejecutantes" de reservar estos 
sitios para exclusivas actividades sociales y simbólicas, las cuales estarían condicionadas para la representación de máscaras. A favor de este razonamiento se aprecia que si bien algunos motivos presentan una tonalidad rojo-oscuro (GE-CO5-3/ver Tabla 1), la mayor parte de las pinturas presentan una tonalidad similar a motivos presentes en otros sitios del área. En desmedro de esta posibilidad, se considera la escasa presencia de "mascariformes o máscaras" en el registro rupestre del norte patagónico, así como su ausencia absoluta en el resto de la región sureña, donde se encuentra representada la TAGC. Cabe recordar que en la región pampeana, además de los motivos descritos en Ventania, las máscaras o caras solo están presentes en un sector estratégico del sitio Haras Los Robles en el sistema de Tandilia.

El segundo razonamiento es apoyado por fuentes etnohistóricas y por relatos de los habitantes actuales, los que aportarían evidencias positivas en cuanto al empleo de esta cueva para eventos simbólicos en tiempos recientes, es decir, en momentos posteriores al contacto hispano-indígena. Objetando este segundo razonamiento se asume como elemento determinante las características topográficas y morfológicas de la Gruta de los Espíritus. En los sitios con arte rupestre del sistema de Ventania existe una fuerte vinculación de aspectos paisajísticos entre las cuevas o aleros y las representaciones rupestres. En su mayor parte se localizan próximas a las nacientes fluviales y tienen una amplia visibilidad del paisaje. Estos elementos apoyarían la idea de que Gruta de los Espíritus debió haber sido reconocida y por lo tanto abordada por las sociedades indígenas en diferentes momentos del Holoceno (Oliva 2000). Otro elemento colateral, aunque no aporta a la discusión cronológica de esta cueva, es el registro de algunos escasos artefactos líticos presentes, como un núcleo agotado, un producto de talla (Oliva, 2000), lo cual en principio estaría denotando que otras actividades de carácter cotidiano se habrían llevado a cabo en el ámbito de esta cueva.

Finalmente, en relación con la tercera hipótesis de discusión presentada, es decir, la resignificación continua de los motivos rupestres, desde una perspectiva teórica, este razonamiento tendría mayor verosimilitud que los dos propuestos previamente. Se considera que el arte rupestre aporta a la comprensión de otras sociedades, y su aplicación provee información de las características percibidas en el mundo material. En tal sentido, se coincide con la propuesta de Baumgarten (1961 [17501758]), quien reflexionó sobre el concepto de estética y lo aplicó a la experiencia estética subjetiva, como un punto intermedio entre el entendimiento y la sensibilidad. Tal situación puede ser aplicable a las sensaciones que ofrece el arte rupestre como resultado de la experiencia estética tanto de su realizador como del observador y, por lo tanto, permite conclusiones sobre las diferentes vinculaciones entre productor/realizador (emisor del mensaje) y el espectador/consumidor/observador (receptor del mensaje) (Mendiola 2002).

Particularmente, en el caso aquí presentado, un elemento significativo es la variabilidad de motivos presentes en la Gruta de los Espíritus (Tablas 1 y 2), lo cual podría estar indicando resignificaciones de ideas similares sobre sucesivas situaciones análogas. Asimismo, esta variabilidad de motivos debe ser considerada en conjunto con la ubicación de las representaciones de los motivos en puntuales sectores jerarquizados de los dos sitios presentados, y es allí donde la perspectiva estética responde a un compromiso sensible, imaginativo y cognitivo con la forma en que se presenta cada situación, teniendo en cuenta que las representaciones rupestres no conforman un objeto exclusivamente valorado desde la perspectiva estética. Otro elemento a tener en cuenta es la ubicación estratégica en el paisaje, tanto de la Gruta de los Espíritus como del sitio 1 Alero Corta Pies. Se considera que estos sitios se asocian a una topografía que permite considerarlos como portales simbólicos o de lo supranatural. Es decir, la localización de estos sitios es posible asociarla a la percepción de la distribución de poderes naturales en el paisaje, la cual reflejaría una parte de la organización social (Whitley 1998). Estas poblaciones no representarían vinculaciones directas con sus pares patagónicos, sino que las representaciones de máscaras con características formales semejantes a las presentes, fundamentalmente en Malargue (Mendoza), serían expresiones de grupos humanos que de alguna manera se vinculaban con los hacedores de los motivos representados en la región cuyana y tal vez producto de reelaboraciones de significados de antiguas representaciones en áreas trasandinas.

Se considera que las representaciones presentes en el sistema de Ventania son, por lo tanto, resignificaciones sucedidas en el tiempo y, por consiguiente, su "construcción" ocurrió en diferentes momentos mediante sucesivas visitas a estos particulares sitios por parte de las sociedades indígenas, situación que, como se expresó, continuó hasta tiempos recientes. De esta manera, se asume que la forma en que se experimenta el mundo desde un enfoque estético comprende otros tipos de procesos, ya que una representación visual implicaría un proceso de reflexión sobre lo que se pinta así como en dónde y cómo se disponen los diversos elementos, alcanzando un valor estético, pues se consigue alterar el sentido y sentimiento del observador; es decir, las cualidades estéticas están en relación con la capacidad 
de determinados tipos de objetos de conquistar sensorialmente a otros. Esta interpretación ha sido considerada en vinculación con el sur de Mendoza y el área del Norte Chico de Chile por Shobinger (1978) y también por González (1989). Este último autor propuso una posible fuente de inspiración de esas cabezas empenachadas de El Molle en los tejidos Parakas, aunque reconoce que si bien son expresiones distintas, registran algunos detalles (pequeños apéndices en lo alto de las figuras) que indicarían una "idea en común" que fue sufriendo transformaciones, y en Cuyo, con el paso del tiempo, agregaron un cuerpo en el extremo inferior (González 1989: 75).

Sin asumir una comunión directa con las ideas propuestas por Shobinger y González, así como partiendo de conceptos teóricos distintos, es, sin embargo, oportuno rediscutir la información ofrecida, dadas las características formales y de detalles registradas en el arte rupestre del sur de Mendoza, para establecer comparaciones, en este caso, con las representaciones presentes en los sitios con motivos de "máscaras" de la Sierra de la Ventana. Por otra parte, resulta relevante para esta discusión la información obtenida en el sistema de Tandilia, en donde, en un contexto amplio de motivos que pueden ser asignados a la TAGC, se registra la representación de un óvalo que constituiría una cara representada en el borde exterior del techo del sitio Haras Los Robles (Mazzanti \& Valverde 2003: 313). Esta representación puede ser entendida como de alto valor simbólico para el conjunto rupestre del sistema de Tandilia, dada su localización en el conjunto rupestre regional, así como su ubicación en un sector muy particular del sitio. Se estima que este grupo de máscaras subcirculares presente en el extremo oriental del sistema de Tandilia, así como aquellas del sistema de Ventania, en la Gruta de los Espíritus en el sitio 1 Alero Corta Pies y en diversos sitios del sur de Mendoza (Malargüe), estarían constituyendo indicadores culturales entre el territorio pampeano con poblaciones procedentes del oeste del país y con cierta posibilidad a su vez de pertenecer a un circuito mayor de poblaciones trasandinas (González 1989; Shobinger 2002), reflejando un conjunto de redes sociales que de alguna manera estarían funcionando a nivel macro regional.

En relación con los relatos sobre la utilización de la Gruta de los Espíritus para realización de rogativas (Bengoa 1987; Mora Penroz 1998; Bechis 1999), estos denotarían la continuidad del uso de estos sitos en el tiempo, en este caso, para fines exclusivamente cargados de significación ritual y las consecuentes resignificaciones de las representaciones. La variabilidad de motivos presentes y las características intrínsecas de los mismos podrían estar indicando diferentes "momentos" en la construcción de este espacio simbólico en la Gruta de los Espíritus. Esta situación apoyaría la idea de una "monumentalización" de un sitio en el paisaje, en el sentido de Criado Boado (1991), probablemente producto de actos que se habrían realizado en diferentes momentos del Holoceno. La llamativa no presencia de la TAGC, es decir, del "arte rupestre norpatagónico" en la Gruta de los Espíritus y en el sitio 1 Alero Corta Pies, podría reflejar "acuerdos forzados" sobre la no apropiación de determinados sitios en el área, en este caso por las poblaciones que sí han representado en diferentes sitios de Ventania expresiones asignables a la TAGC.

Paralelamente a la discusión simbólica de la representación de máscaras, el conjunto de evidencias presentadas en este trabajo propone argumentos que enriquecen el debate sobre la ocupación del sector sur de la región pampeana. Este poblamiento ocurrido en distintos momentos del Holoceno estuvo, entre otros factores, condicionado por diversas cuestiones, algunas de tipo ambiental, que activaron procesos de ocupación y restricción de las poblaciones. Dada la variabilidad de información presentada, se piensa que en el desarrollo de estos procesos interactuaron variables de complejidad social y simbólicas, que sugieren que el comportamiento observado no respondería solo a la posibilidad de los recursos, sino que su respuesta sería el resultado de situaciones sociales, de poder, manejo del territorio, cuestiones simbólicas y sucesivas resignificaciones de las sociedades que ocuparon el territorio.

Finalmente, se estima que la representación de máscaras o mascariformes presente en Sierra de la Ventana ha posibilitado una interacción entre los diferentes actores que han "reinterpretado o resignificado" estos motivos rupestres, originándose un diálogo en que se expresa que la vivencia estética se representa por una experiencia del conocimiento sensible y propia de la actividad humana (Goodman 1990; Schaeffer 2005). En tal sentido, este tipo de representaciones ha sido abordada como una especie de red simbólica, estableciéndose un orden mediante la articulación de sus unidades de significación; es decir, partiendo de la búsqueda de la comprensión de su contenido se logra analizar sus estructuras y visualizar la red simbólica que las articula, para lo cual se han considerado las cualidades de las representaciones en convivencia con la habilidad o competencia de los grupos receptores para su descubrimiento, localización y la construcción de las distintas resignificaciones. 
RECONOCIMIENTOS A la memoria de Eduardo Holmberg, con quien comparto el mágico interés de su descubrimiento. A Martina Oliva y Cecilia Panizza, por el tratamiento de las imágenes. La familia Sbarbatti ha sido otro importante sostén de la conservación y posibilitó el estudio de la Gruta de los Espíritus, a pesar de las dificultades e incomprensión de muchos indoctos furtivos. Estos estudios se enmarcan en proyectos acreditados por la Facultad de Ciencias Naturales y Museo de la Universidad Nacional de La Plata y la Facultad de Humanidades y Artes de la Universidad Nacional de Rosario, y ha contado con la colaboración de la Dirección Provincial del Instituto Cultural del Gobierno de la Provincia de Buenos Aires.

\section{REFERENCIAS}

Albornoz, A., 2003. Estudios recientes del arte rupestre en la provincia de Río Negro. En Arqueología de Río Negro, C. Gradin, A. Aguerre \& A. Albornoz, Eds., pp. 79-107. Secretaría de Estado de Acción Social de Río Negro: Carmen de Patagones, Imprenta Minigraf.

Albornoz, A. \& I. Pereda, 2010. La interacción con particulares y su importancia en la preservación. Análisis de caso: Estancia los manantiales, meseta de somuncurá. En Arqueología argentina en los inicios de un nuevo siglo. Tomo 3. Publicación del XIV Congreso Nacional de Arqueología Argentina, F. Oliva, N. de Grandis \& J. Rodríguez, Comps., pp. 287-298, Rosario.

Austral, A., 1994. Arqueología en el sudoeste de Buenos Aires. Resúmenes XI Congreso Nacional de Arqueología Argentina, pp. 201-203. San Rafael, Mendoza.

Barrientos, G.; M. LeIPus \& F. Oliva, 1999. Investigaciones arqueológicas en laguna Los chilenos (provincia de Buenos Aires). En Arqueología pampeana en los '90, M. Beron \& G. Politis, Eds., pp. 115-126. San Rafael, Museo de Historia Natural de San Rafael.

Baumgarten, A. G. 1961 [1750-1758]. Aesthetica Scripsit. Hildesheim: G. Olms.

Bechis, M., 1999. Los lideratos políticos en el área arauco-pampeana en el siglo XIX: ¿poder o autoridad? En Etnohistoria, NAyA Noticias de antropología y arqueología. Buenos Aires.

Belardi, J., 2004. Más vueltas que una greca. En contra viento y marea. Arqueología de Patagonia, T. Civalero, P. Fernández \& A. Guráieb, Comps., pp. 591-603. Buenos Aires, INAPL, SAA.

Bellelli, C.; V. Scheinson \& M. M. Podestá, 2008. Arqueología de pasos cordilleranos: un caso de estudio en Patagonia norte durante el Holoceno Tardío. Boletín del Museo Chileno de Arte Precolombino 13 (2): 37-55.

BengOA, J., 1987. Historia del pueblo mapuche (siglos XIX y XX). Santiago: Ediciones Sur.

Boschin, M., 1986. Arqueología del "área pilcaniyeu". Sudoeste de Río Negro, Argentina. Cuadernos del Instituto Nacional de Antropología 11: 19-99.

2009. Tierra de hechiceros. Arte indigena de Patagonia septentrional argentina. Ediciones Universidad de Salamanca y servicio de publicaciones de Universidad de Córdoba (España).

Cabello, G., 2011. De rostros a espacios compositivos: una propuesta estilística para el valle Chalinga, Chile. Chungara 43 (1): 25-36.

Casamiquela, R., 1981. El arte rupestre de la Patagonia. Buenos Aires: Siringa libros.

CAsimir, M., 1992. The dimensions of territoriality: An introduccion. En Mobility and territoriality, M. Casimir \& A. Rao, Eds., pp. 1-26. Oxford.

CASTRO, A., 1983. Noticia preliminar sobre un yacimiento en la Sierra de la Ventana, Provincia de Buenos Aires. Relaciones de la Sociedad de Antropología Argentina 15: 91-107, Buenos Aires.

Catella, L.; J.Moirano \& F. Oliva, 2010. Disponibilidad de materias primas líticas y su importancia para el análisis del uso del espacio y la organización de la tecnología de sociedades cazadoras recolectoras. En Mamül mapu, M. Berón, L. Luna, M. Bonomo, C. Montalvo, C. Aranda \& M. Carrera, Eds., pp. 239-253. Santa Rosa: Universidad Nacional de la Pampa.

Ceresole, G. \& J. Slavsky, 1985. Informe preliminar sobre la localidad Lobería 1 (provincia de Buenos Aires). En VIII Congreso Nacional de Arqueología Argentina. Resúmenes de los Trabajos a Presentarse (Comunicaciones y Ponencias), p. 4. Concordia, Entre Ríos.

CONSENS, M., 1986. San Luis - el arte rupestre de sus sierras. San Luis: Fondo editorial Sanluiseño, Dirección provincial de cultura. 1995. Rock arte sites of southeastern South America. En Rock art studies in the Americas, J. Steimbring, Ed., pp. 151-163. Inglaterra.

Consens, M. \& F. Oliva, 1999. Estado de las investigaciones en sitios con representaciones rupestres en la región pampeana, República Argentina. En Actas del XI Congreso Nacional de Arqueología Argentina, pp. 218-228. La Plata.

Criado-Boado, F., 1991. Construcción social del espacio y reconstrucción arqueológica del paisaje. Boletín de Antropología Americana 24: 5-29. España.

CuRTONI, R., 2006. Expresiones simbólicas, cosmovisión y territorialidad en los cazadores-recolectores pampeanos. Relaciones de la Sociedad Argentina de Antropología 21: 133-160. Buenos Aires.

Gamble, C., 1990. El poblamiento paleolítico de Europa. Barcelona: Ed. Crítica.

GILI, M., 2000. Motivos abstractos en el arte rupestre de cerro Intihuasi. Río cuarto Córdoba. En Arte en las rocas. Arte rupestre, menhires y piedras de colores en Argentina, M. M. Podestá \& M. de Hoyos, Eds., pp. 129-134. Buenos Aires: Sociedad Argentina de Antropología.

Giménez, G. \& C. HÉAu Lambert, 2007. El desierto como territorio, paisaje y referente de identidad. Culturales 3 (5): 7-42.

GonZÁlez, A., 1989. El arte rupestre del Tolar (Catamarca). Argentina indígena de un país. Apéndices de summa andina: 68-77.

Goodman, N., 1990. Maneras de hacer mundos. Madrid: Visor.

Gradin, C., 1975. Contribución a la arqueología de la pampa. Dirección provincial de cultura de la Pampa.

Gradin, C., 1977. Pintura rupestre del alero cárdenas (Santa Cruz). Relaciones de la Sociedad de Antropología Argentina 11: 143-158.

HajDuk, A. \& A. AlborNoz, 1999. El sitio valle encantado I, su vinculación con otros sitios: un esbozo de la problemática local diversa del Nahuel Huapi. En Soplando en el viento. Actas de la III Jornadas de Arqueología de la Patagonia, M. Civalero, P. Fernández \& A. Guraieb, Comps., pp. 371-391. Universidad Nacional del Comahue.

Harrington, H., 1947. Hojas geológicas $33 m$ y $34 m$. Sierras de Curamalaly de la Ventana. Provincia de Buenos Aires. Ministerio de Industria y Minería de la nación.

HaYden, B., 1981. Research and development in the Stone Age: Technological transitions among hunter-gatherers. Current Anthropology 22: 519-548.

HeYD, T., 2003. Rock art aesthetics and cultural appropriation. The journal of aesthetics and art criticism 61 (1): 37-46. 2003-2004. Estética del arte rupestre: trazo en la roca, marca del espíritu, ventana al paisaje. Espacio, tiempo y forma, serie I, Prehistoria y Arqueología 16-17: 123-230. Uned.

Holmberg, E., 1884. La sierra de Curá-malal (Currumalan). Informe presentado al excelentísimo Señor Gobernador de la Provincia de Buenos Aires, dr. Dardo Rocha. Buenos Aires.

INGOLD, T., 1986. Territoriality and tenure: The appropriation of space in hunting and gathering societies. En The appropriation of nature, T. Ingold, Ed., pp. 130-164. Manchester: Manchester University press.

Jochiм, M., 1981. Strategies for survival. Cultural behavior in an ecological context. Nueva York: Academic press.

KeEley, L., 1988. Hunter-gatherer economic complexity and population pressure: A cross-cultural analysis. Journal of Anthropological Archaeology 7: 373-441 
Leroi-Gourhan, A., 1971. El gesto y la palabra. Universidad Nacional de Venezuela: Ediciones de la Biblioteca

Lévi-Strauss, C., 1981. La vía de las máscaras. México: Siglo xxi.

MaNTHA, A., 2009. Territoriality, social boundaires and ancestor veneration in the central Andes of Perú. Journal of Anthropological Archaeology 28: 158-176.

MazzanTi, D., 1991. Haras los robles: Un sitio con pictografías en el borde oriental de las sierras de Tandilia. Boletín del Centro 3: 180-200.

Mazzanti, D. \& F. Valverde, 2003. Representaciones rupestres de cazadores-recolectores en las sierras de Tandilia oriental: Una aproximación a la arqueología del paisaje. En Actas del XIII Congreso Nacional de Arqueología Argentina, pp. 313-316. Córdoba.

Mendiola, G., 2002. Arte rupestre: Epistemología, estética y geometría. Sus interrelaciones con la simetría de la cultura. Ensayo de explicación sobre algunas ideas centrales de Adolfo Best Maugard y Beatriz Braniff. <http://rupestreweb.tripod.com/ mendiola2.html $>$ [Citado 09-12-13].

Menghin, O., 1952. Las pinturas rupestres de la Patagonia. Runa V: 5-2. Buenos Aires.

1957. Estilos del arte rupestre de Patagonia. Acta Praehistórica I: 57-87. Buenos Aires.

Morphy, H., 1994. The interpretation of ritual reflections from film on anthropological practice. Man (N.S.) 29: 117-146.

Mora Penroz, Z., 1998. La araucanía mística antigua para la grandeza de Chile. Chile: Telstar impresiones.

Mostny Glaser, G. \& H. Niemeyer Fernandez, 1983. Arte rupestre chileno. Serie el patrimonio cultural chileno colección historia del arte chileno. Santiago: Publicación del Departamento de Extensión Cultural del Ministerio de Educación.

NACuzZI, 1., 1998. Identidades impuestas. Tehuelches, aucas y pampas en el norte de la Patagonia. Buenos aires: Sociedad Argentina de Antropología.

Oliva, F., 1991. Investigaciones arqueológicas desarrolladas en el sector occidental del sistema de Ventania y la llanura adyacente. 1987-1989. Boletín del Centro 1: 39-41.

2000. Análisis de las localizaciones de los sitios con representaciones rupestres en el sistema serrano de Ventania, Provincia de Buenos Aires. En Arte en las rocas. Arte rupestre, menhires $y$ piedras de colores en Argentina, M. M. Podestá \& M. de Hoyos, Eds., pp.143-158. Buenos Aires: SAA y Asociación de Amigos del INA.

2006. Usos y contextos de producción de elementos "simbólicos" del sur y oeste de la provincia de Buenos Aires (República Argentina). Revista de la Escuela de Antropología XII: 101-116. Rosario.

2010. Análisis de la evolución del uso del espacio del área ecotonal húmeda seca pampeana. III Jornadas de Ciencia y Tecnología de la UNR, pp. 225-227. Rosario: Secretaría de ciencia y tecnología de la UNR.

Oliva, F. \& M. Algrain, 2004. Una aproximación cognitiva al estudio de las representaciones rupestres del Casuhati (sistema serrano de Ventania y llanura adyacente, Provincia de Buenos Aires). En La región pampeana: Su pasado arqueológico, C. Gradin \& F. Oliva, Eds., pp. 49-60. Rosario: Laborde.

2005. Representaciones simbólicas de las sociedades indígenas en el área ecotonal húmeda-seca pampeana (AEHSP). ¿Arte shamánico? Revista de la Escuela de Antropología de Rosario x: 155-168. Rosario.

Oliva, F. \& J. Moirano, 1999. Primer informe sobre aprovisionamiento primario de riolita en sierra de la Ventana (Provincia de Buenos Aires, Argentina). En Arqueología pampeana en la década de los '90, M. Berón \& G. Politis, Eds., pp.137-146. Olavarría: INCUAPA, UNPBA y Museo Nacional de Historia Natural de San Rafael.
Oliva, F. \& M. C. Panizza, 2007. Estilos, agrupamientos y temas en el análisis de las representaciones rupestres. El sistema serrano de Ventania como caso de estudio. En Actas del XVI Congreso Nacional de Arqueología Argentina. Tomo II: 463-467. San Salvador de Jujuy.

2012. Primera aproximación a la arqueología monumental del sistema serrano de Ventania, Provincia de Buenos Aires. Anuario de Arqueología 4: 161-180. Rosario.

Oliva, F. \& A. SÁnchez, 2001. Uso y valorización del patrimonio arqueológico rupestre en la región pampeana argentina mediante el empleo de técnicas informáticas. Presentado en el Taller internacional de arte rupestre de la Habana, Cuba.

Oliva, F.; A. GIL \& M. ROA, 1991. Recientes investigaciones arqueológicas en el sitio San Martín 1 (BU/PU/5), partido de Puán, Provincia de Buenos Aires. Shincal 3: 135-139.

Oliva, F.; J. Motrano \& M. SAgHeSSI, 1991. Recientes investigaciones en el sitio laguna de Puán 1. Boletín del Centro 2: 127-138.

Oliva, F.; M. C. Panizza \& M. Algrain, 2010. Diferentes enfoques en la investigación del arte rupestre del sistema serrano de Ventania. Comechingonia 13: 89-107.

Oliva, F.; G. L'Heureux, H. De Angelis, V. Parmigiani \& F. Reyes, 2007. Poblaciones indígenas de momentos post-contacto en el borde occidental de la Pampa húmeda: Gascón 1, un sitio de entierros humanos. En Arqueología argentina en los inicios de un nuevo siglo, F. Oliva, N. De Grandis \& J. Rodriguez, Eds., pp. 265-174. Rosario: Laborde libros editor.

Ouzman, S., 1998. Towards and mindscape of landscape: rock- art as expression of world- understanding. En The archaeology of rock-art, C. Chippindale \& P. S. C. Taçon, Eds., pp. 30-41. Cambridge: Cambridge University Press.

Podestá, M. M.; C. Bellelli, R. Labarca, A. Albornoz, A. Vasiniy \& E. Tropea, 2008. Arte rupestre en pasos cordilleranos del bosque andino patagónico (El manso, Región de los Lagos y Provincia de Río Negro, Chile-Argentina). Magallania 36 (2): 145-156. Chile.

Podestá, M. M.; F. Oliva \& A. Florines, 2011. Indicadores estilísticos de interacción a través del arte rupestre de Pampa-Patagonia y Cuenca del Plata (Argentina-Uruguay). En Actas del I Congreso Internacional de Arqueología de la cuenca del Plata, IV Encuentro de Discusión Arqueológica del Nordeste Argentino y las II Jornadas de Actualización en Arqueología tupiguaraní, pp. 175-176. Buenos Aires.

Priegue, C. N., 1997. Shamanismo y hechicería en la cultura tehuelche meridional. En Shamanismo sudamericano, J. Schobinger, Comp., pp. 87-92. Buenos Aires: Editorial Almagesto.

Rocchietti, A., 1990. Arte étnico del sur de Córdoba: Estilo Cuatro vientos-achiras. Revista de la Universidad Nacional de Río Cuarto 10 (2): 133-146.

SCHAEFFER, J. M., 2005. Adiós a la estética. Madrid: Móstoles.

SHOBinger, J., 1978. Nuevos lugares con arte rupestre en el extremo sur de la Provincia de Mendoza. Relaciones de la Sociedad Argentina de Antropología 12: 175-182.

2002. Arte rupestre del departamento Malargüe. En Entre montañas y desiertos: Arqueología del sur de Mendoza, A. Gil \& G. Neme, Eds., pp. 181-194. Buenos Aires: Publicaciones de la Sociedad Argentina de Antropología.

SCHiller, W., 1930. Investigaciones geológicas en las montañas del sudoeste de la Provincia de Buenos Aires. En Anales del Museo de la Plata. Tomo Iv, primera parte (segunda serie): 11-96. La Plata.

Suero, T., 1972. Compilación geológica de las sierras australes de la Provincia de Buenos Aires. Mop. Lemit. Ministerio de obras públicas, Lemit, División Geología. En Anales 3: 135-147, La Plata.

TAPIA, A., 1937. Las cavernas de ojo de agua y las hachas. Boletín 43: 1-122. Buenos Aires: Dirección de Minas y Geología. 
Troncoso, A.; F. Armstrong, F. Vergara, P. Urzúa \& P. Larach, 2008. Arte rupestre en el valle el encanto (Ovalle, Región de Coquimbo): Hacia una revaluación del sitio-tipo del Estilo Limarí. Boletín del Museo Chileno de Arte Precolombino 13 (2): 9-36.

WANDSNIDER, L., 1992. Archaeological landscapes studies. En Space, time, and archaeological landscapes, J. Rossignol \& L. Wandsnider, Eds., pp. 285-292. Nueva York: Plenum press.
Whitley, D., 1998. New approaches to old problems. Archaeology in search of an ever elusive past. En Reader in archaeological theory. Post-processual and cognitive approaches, D. Whitley, Ed., pp. 1-28. Londres: Routledge. 